\title{
Awakening the oocyte: controlling primordial follicle development
}

\author{
Eileen A McLaughlin ${ }^{1,2}$ and Skye C Mclver ${ }^{1}$ \\ ${ }^{1}$ Reproductive Science Group, School of Environmental \& Life Sciences and ${ }^{2}$ ARC Centre of Excellence in \\ Biotechnology \& Development, University of Newcastle, Callaghan, New South Wales 2308, Australia
}

Correspondence should be addressed to E A McLaughlin at Reproductive Science Group, School of Environmental \& Life Sciences, ARC Centre of Excellence in Biotechnology \& Development, University of Newcastle, Callaghan, New South Wales 2308, Australia; Email: eileen.mclaughlin@newcastle.edu.au

\begin{abstract}
Oocytes are sequestered in primordial follicles before birth and remain quiescent in the ovary, often for decades, until recruited into the growing pool throughout the reproductive years. Therefore, activation of follicle growth is a major biological checkpoint that controls female reproductive potential. However, we are only just beginning to elucidate the cellular mechanisms required for either maintenance of the quiescent primordial follicle pool or initiation of follicle growth. Understanding the intracellular signalling systems that control oocyte maintenance and activation has significant implications for improving female reproductive productivity and longevity in mammals, and has application in domestic animal husbandry, feral animal population control and infertility in women.

Reproduction (2009) 137 1-11
\end{abstract}

\section{Introduction}

In mammals, the functional oocytes that give rise to offspring are sequestered in primordial follicles before birth and remain quiescent in the ovary, often for decades, until recruited into the growing pool throughout the reproductive years (Reynaud \& Driancourt 2000, Choi \& Rajkovic 2006a). Many years of research have demonstrated that control of primordial follicle activation requires complex bidirectional signalling between the oocyte and the surrounding somatic cells, involving specific cytokines and growth factors (Skinner 2005, Hutt et al. 2006b). In contrast, the intracellular signalling pathways activated during follicle development remain largely uncharacterized and are fundamental to understanding the molecular systems responsible for ensuring timely delivery of functional oocytes for fertilization. An improved understanding of these basic cellular mechanisms of ovarian physiology will inform biotechnology strategies for the manipulation of reproductive productivity in domesticated livestock (Hunter et al. 2004), the enhancement of protocols for the retention of fertility in endangered native species (Pukazhenthi et al. 2006) and the development of novel humane methods of pest animal population control (McLaughlin et al. 2003). Similarly, new insights into these fundamental processes have the potential to be therapeutically employed to improve reproductive health and productivity in women choosing to start families in later life (Baird et al. 2005), those who are likely to experience premature ovarian failure (POF; Mahmoud et al. 2007) and those women seeking to reserve healthy oocytes for future use, for instance, prior to chemotherapy (Demeestere et al. 2007).

\section{Ovarian folliculogenesis and reproductive aging}

Oocytes in mammals develop from primordial germ cells (PGCs) that migrate early in development to the naive gonad to become oogonia. Folliculogenesis begins with recruitment of pregranulosa cells to the oocyte to form the primordial follicle in the foetal or neonatal ovary (see Fig. 1; Picton et al. 1998). At this stage, the oocyte is arrested in meiotic prophase I and only re-enters meiosis or germinal vesicle breakdown upon ovulation (Picton et al. 1998). From the pool of primordial follicles, some are stimulated to grow and enter development into primary, secondary or antral follicles (Skinner 2005; see Fig. 1). By the time the follicle has reached the pre-antral stage, the oocyte has enlarged considerably, synthesized the extracellular zona pellucida and is surrounded by proliferating granulosa cells. During the final stages of antral follicle development, the oocytes become competent enough to resume the meiotic process (Zheng \& Dean 2007) and prior to ovulation, a LH surge causes nuclear maturation, culminating in the completion of the first meiotic division and extrusion of the first polar body, followed by re-arrest at metaphase II of meiosis II (Hutt \& Albertini 2007). In mammals, the advent of reproductive 



Figure 1 Confocal images of murine ovarian tissue triple labelled with rhodamine-conjugated Pisum sativum lectin (red), FITC-conjugated wheat germ agglutinin lectin (green) and the DNA-specific dye TOPRO3 (blue). (A) Neonatal ovary containing both primordial and primary follicles. (B) Enlarged image of primordial follicle.

senescence reveals that the loss of ovarian function (or menopause) occurs at a relatively young age compared with other physiological systems. As the primary determinant of reproductive performance in female mammals is the size and longevity of the primordial follicle pool, methods of estimating the reproductive age, opposed to chronological age, have determined that the rate of decline in quiescent functional follicles in the adult ovary increases with age (Hansen et al. 2008).

\section{Timing and control of primordial follicle formation}

Migration of PGCs from the epithelium of the yolk sack, through the embryonic hindgut, to eventually colonize the gonadal ridge is controlled and directed by the secretion of pleiotrophic cytokines and growth factors, such as SCF and CXCL12 (for reviews see (Molyneaux \& Wylie 2004, Kunwar et al. 2006)). On arrival at the genital ridge the PGCs migrate inwards to form the primitive medullary and sex cords, where they lose their motility and in females become oogonia (Baker \& Franchi 1967, Sathananthan et al. 2000). Dividing oogonia are found clustered together in oogonial nests, which are connected by intercellular bridges (Pepling \& Spradling 1998, 2001, Pepling 2006). On cessation of mitosis, the oogonia enter the early stages of meiosis I as primary oocytes. Somatic cells invade the cortex from the medullar and now surround the oogonial nests (Gondos 1987a, 1987b). Interestingly, those cells in the inner gonad appear to be the first oocytes to enter meiosis while those located at the periphery are the last to do so (Edwards et al. 1977, van Wezel \& Rodgers 1996) and this may have consequences for the timing of primordial follicle activation. Oocytes then lose their intercellular bridges and become enclosed in a layer of flattened pregranulosa cells, thought to be derived from mesonephric, or surface epithelial, cells (McNatty et al. 2000) though this is a matter of some debate (see (Maheshwari \& Fowler 2008)). Finally, the somatic cellsurrounded oocytes arrest in meiotic prophase I at diplotene, becoming the primordial follicles (Baker \&
Franchi 1967). In the human ovary, the first primordial follicles are detected in mid-gestation and in rodents 2-4 days post-birth (Hirshfield 1991, Sforza \& Forabosco 1998) and recent studies have suggested that changes in the levels of maternal and foetal oestradiol and progesterone regulate primordial follicle assembly (Kezele \& Skinner 2003, Britt et al. 2004, Nilsson et al. 2006b, Chen et al. 2007).

\section{Transcriptional control of primordial follicle formation}

Phenotypic analysis of mice null for a number of transcription factors has been central to our ability to identify concomitant crosstalk between signalling pathways in oogenesis and early folliculogenesis and these transcription factors have been postulated to be candidate genes for POF in humans (Suzumori et al. 2007).

One of the first transcription factors found to have a role in primordial follicle formation was factor in the germ-line $\alpha$ (Fig $\alpha$ or Figla), which is a basic helix-loophelix transcription factor that binds as a heterodimer to the Ebox elements found in the promoters of the ZP genes to control their expression (Liang et al. 1997). Primordial follicle formation appears to be directed by the transcription factor Figla, which is expressed by the oocyte (Soyal et al. 2000). Figla is expressed in the female mouse gonad at embryonic day 13 but its expression is reduced between post-natal day 7 and 14; however, residual transcripts are found in the adult ovary. Phenotypic analysis of the homozygous null female mouse confirmed sterility while the male was fertile. Histological assessment revealed that the female ovary was found to contain no germ cells and that this was a result of the inability of the germ cell nests to break down and form follicles within the post-natal day 0 ovary. In late embryogenesis, the oocytes did not proceed to the diplotene stage of meiosis, and instead these germ cells died. Gene expression analysis indicated that the oocytes of the null mice did not express any zona pellucida (ZP) gene (Soyal et al. 2000). 
More recent studies have revealed that Figla has also been found to up-regulate several genes including Pou5f1, Zp2, Ivns1abp, Vbp1, Padi6 and Rbpms2 and to down-regulate Sp3, Hdac2 and Ogt. Several testisspecific genes are also down-regulated by the presence of Figla in oocytes that if expressed might disrupt normal oogenesis (Joshi et al. 2007). Foxc1 is a forkhead/winged helix transcription factor, and while disruption of this gene does not interfere with the assignment of PGCs, the migration of these cells is disrupted with only a quarter of the population reaching the genital ridges (Mattiske et al. 2006). However, once in the ovary the PGCs proliferate normally but the supporting tissue is not arranged correctly, and the primordial follicles are not organized correctly (Mattiske et al. 2006). These mutants die at birth but analysis of transplanted ovaries in ovariectomized females determined that the germ cells undergo folliculogenesis; however, the theca and the granulosa cells are not well organized and the antrum does not form. Since Foxc1 is not expressed in the oocyte, the authors surmised that it may be required by the granulosa cells to respond to signals from the oocyte (Mattiske et al. 2006).

\section{Post-natal oogenesis in mammals}

In 2004, the prevailing dogma that the primordial follicle population is finite (Zuckerman 1951), was challenged (Johnson et al. 2004). Initial reaction included the re-appraisal of data pertaining to older studies (Byskov et al. 2005) and new studies in traditional (Liu et al. 2007 C, Begum et al. 2008) transplantation (Johnson et al. 2005, Lee et al. 2007a), parabiotic (Eggan et al. 2006) and null mouse models systems (Lee et al. 2007b). This was accompanied by the publication of a number of review and commentary articles (Telfer et al. 2005, Hutt \& Albertini 2007) with the existence and function of these 'Tilly' follicles fiercely contested (Johnson et al. 2005, Skaznik-Wikiel et al. 2007, Tilly \& Johnson 2007, Tilly \& Rueda 2008, Tilly et al. 2008). Several researchers have sought to produce independent evidence of the existence of post-natal oogenesis in adults with conflicting results (Kerr et al. 2006) and while most studies conclude that these newly formed follicles do not contribute to the pool of ovulated oocytes there is some conjecture that these 'follicles' may play a role in providing support for the depleted ovarian reserve (Lee et al. 2007a, 2007b).

\section{Regulation of activation and apoptosis in the primordial follicle population}

Many questions remain definitively unanswered regarding the regulation of primordial follicle population dynamics. Of key interest are the mechanisms by which a particular follicle is selected to grow while those immediately adjacent remain quiescent. One popular proposition is known as the 'production-line' hypothesis (Henderson \& Edwards 1968), in which the first oocytes to enter meiotic arrest during embryonic gonad development are, in fact, also the first oocytes to activate in adult life. The rationale behind this hypothesis is that mature oocytes produced in late mammalian female life are more likely to be chromosomally imbalanced or aneuploid as they are the last oocytes to enter meiotic arrest and are dysfunctional due to the presence of fewer chiasmata and univalent pairs (Henderson \& Edwards 1968). Observation of neonatal ovarian development supports this hypothesis as the oocytes deposited closest to the corticomedullary junction undergo rapid meiotic progression, become primordial follicles and are among the first to activate, whereas oocytes located further within the cortex undergo slower meiotic progression and activate later in life (Hirshfield 1991). Initial evidence using radiolabelling to support this hypothesis that follicle do not activate and mature at random (Polani \& Crolla 1991, Hirshfield 1992) conflicted with the in vitro data indicating that in culture the majority of the primordial follicles would activate simultaneously (Wandji et al. 1996) and thus initiation of growth of primordial follicle was probably subject to extrinsic factors (Eppig \& O'Brien 1996). Attempts to solve this conundrum using 5-bromo-2'-deoxyuridine (BrdU) labelling of follicles in utero met with limited success (Meredith \& Doolin 1997), though did partially support the 'production-line' hypothesis. The situation is further complicated by the evidence that the primordial follicle population is heterogeneous based on the mitotic activity of the lineages of the follicle somatic cells. Growth initiation may depend upon the proportion of each of these cell types in the follicle, as each type may have a different threshold for responding to activation or inhibitory cues (Hirshfield 1992).

In the species studied so far, both the age and cyclicity of the animals is crucial, as multiple reports concur that both follicle activation and development are accelerated during the initial waves of folliculogenesis when compared with those in adult cycling animals (Pedersen 1969, Hage et al. 1978). Interestingly, using unilateral ovariectomy, Brook and colleagues (Brook et al. 1984) found in mice that the biological age, rather than the chronological age, had an important influence on oocyte quantity and quality. This is reflected in the studies of human ovarian reserve, where the proportion of follicles that activate appears to depend on the size of the ovarian follicle reserve as there is an apparent inverse correlation between the fraction of growing follicles and the size of the primordial follicle store. Importantly, these histomorphometric analyses have consistently shown an increase in follicle loss in the perimenopausal years in humans (Gougeon et al. 1994, Faddy \& Gosden 1996, Faddy 2000, Hansen et al. 2008), with few of the other 
mathematical models of primordial follicle growth dissenting (Mandl \& Zuckerman 1951).

Elegant work using oocytes and granulosa cells to reconstitute follicles has demonstrated that once activated to grow that oocytes orchestrate and coordinate the development of mammalian ovarian follicles and that the rate of follicle development is controlled by the oocyte (Eppig 2001, Eppig et al. 2002). Thus began the search for intrinsic factor(s) that determined how many follicles begin growing each day (Gougeon \& Chainy 1987) and led to the hypothesis that the accelerated follicle loss observed in neonatal and juvenile animals is due to the absence of an inhibitor produced by mature follicles (Edwards et al. 1977). Moreover, slightly increased serum gonadotrophin levels observed in neonates, juveniles and perimenopausal women may be responsible for the accelerated follicle activation particularly, as recent reports suggest that FSH activity can significantly influence the size of the primordial and early pre-antral follicle populations (Roy \& Albee 2000, Allan et al. 2006), which is in contrast with the widely accepted view of gonadotrophin-independent early folliculogenesis (McGee \& Hsueh 2000).

The vast majority of oogonia and oocytes are lost during embryonic, neonatal and adult life through apoptosis (Kim \& Tilly 2004) and are not destined to produce mature oocytes for fertilization. Arguments that this is a selection mechanism designed to remove abnormal oocytes from the follicle pool are cogent but observations of single cell atresia in oocyte nests during primordial follicle formation (Pepling \& Spradling 2001) indicates that other factors such as somatic cell support may regulate this process.

Knockout mice null for specific transcription factors has illuminated some of the pathways involved in primordial follicle formation and survival. Preferentially expressed in oocytes in the mouse ovary is LHX8, a LIMhomoeobox transcription factor family member. Mice null for LHX8 fail to maintain the primordial follicles that disappear in the first week of life (Choi et al. 2008b) and appears to be caused by a marked reduction in the expression of KIT and KITL in LHX8 null ovaries. POU5F1 (or OCT4) is a transcription factor whose precise targets are not known and its role in oogenesis has only recently been ascribed (Pangas \& Rajkovic 2006). POU5F1 is expressed in PGCs until after they migrate to the naïve gonad and expression is then repressed after the onset of meiotic prophase I in oocytes. POU5F1 is re-expressed after birth and coincides with the growth period of the oocytes (Parfenov et al. 2003). As the phenotype of the POU5F1 null mouse is embryonic lethal, little was known about its post-natal role in the ovary, but analysis of the conditional knockout targeted to the germ cells demonstrates a role in PGC survival. When the POU5F1 conditional oocyte-specific female mice are born, their ovaries contain some oocytes; however, a progressive increase in infertility is observed corresponding to the loss of primordial follicles. At 6 weeks of age, there are almost no follicles within the ovary and this has been attributed to the absence of POU5F1 resulting in significant premature apoptosis in the PGCs prior to colonization of the gonads (Kehler et al. 2004).

\section{Transcript profiling in folliculogenesis}

While ovarian follicle development has been well characterized histomorphologically and the occurrence of naturally occurring KIT mutant mice, such as steel panda (Slpan/Slpan; Hutt et al. 2006b) have given insights into the process of folliculogenesis, it is the advent of state-of-the-art genomic and proteomic approaches that have identified key paracrine and autocrine signalling pathways, associated with the initial signs of primordial follicle activation.

To identify the essential mediators of follicle activation, researchers have obtained and compared ovarian transcriptomes during the crucial phase of primordial to primary follicle transition in the mammalian ovary (Arraztoa et al. 2005, Kezele et al. 2005b, Serafica et al. 2005, Holt et al. 2006). These innovative approaches provided new insights into the candidate regulatory factors and the development of novel mechanistic models for this critical biological process. Key findings included the identification of ligands and their receptors in primordial follicles, which play important roles in the control of the primordial to primary follicle transition and maintenance of quiescence.

Functional analysis using ovarian neonatal in vitro culture systems has confirmed that an ever increasing number of cytokines and pleiotrophic growth factors are known to enhance the rate of activation of primordial follicles (see Fig. 2) including KIT ligand (KITL; Hutt et al. 2006b), leukaemia inhibitory factor (LIF; Nilsson et al. 2002), bone morphogenic proteins (BMP4 and BMP7; Lee et al. 2001, Nilsson \& Skinner 2003, Craig et al. 2007), platelet-derived growth factor (Nilsson et al. 2006a), keratinocyte growth factor (Kezele et al. 2005a), basic fibroblast growth factor (FGF2; Nilsson et al. 2001), glialderived neurotrophic factor (Dole et al. 2008) and the neurotrophins (NGF, NTF5 and BDNF; Dissen et al. 2002, Romero et al. 2002, Spears et al. 2003, Paredes et al. 2004, Dole et al. 2008).

In addition, in vitro culture studies have indicated that $\mathrm{AMH}$ acts to inhibit the primordial to primary follicle transition (Durlinger et al. 2002), with the exception of a recent report in the human where $\mathrm{AMH}$ initiates follicle development (Schmidt et al. 2005). Recently, our genomewide array analyses further identified the chemoattractive chemokine CXCL12, as a second inhibitor of primordial follicle transition (Holt et al. 2006).

Similar to primordial follicle assembly, an endocrine model of the primordial to primary follicle transition has been suggested for the rodent involving the actions of progesterone and oestrogen. In vivo, steroid levels are high in prenatal ovaries due to the maternal influence, 




Figure 2 Ovarian cytokine and growth factor signalling factors - roles in primordial to primary follicle transition. Green arrows are promoters of development and red arrows are inhibitors of follicle activation. Abbreviations: $\mathrm{AMH}$, anti Müllerian hormone; BMP, bone morphogenic protein; FGF, fibroblast growth factor; GDF, growth differentiation factor; GDNF, glial-derived neurotrophic factor; KGF, keratinocyte growth factor; KL, KIT ligand; LIF, leukaemia inhibitory factor; SDF, stromal cell-derived factor. and decline during the first post-natal wave of folliculogenesis in mice. In vitro both hormones act to decrease primordial follicle recruitment during the first wave following birth (Kezele \& Skinner 2003). As progesterone levels have been noted to drop in monkey foetuses at around the time of follicle growth initiation, creating a plausible mechanism for the control of premature recruitment in other species (Kezele \& Skinner 2003). This hypothesis is further supported by studies in the oestrogen-deficient aromatase knockout mouse that display higher numbers of pre-antral and antral follicles by 6 weeks of age than wild-type mice. This observation suggests that the onset of primordial follicle recruitment is temporally retarded by oestrogen (Britt et al. 2004).

\section{Multiple activator and repressor pathways converge to regulate activation of the primordial follicle}

Altogether four lines of evidence suggest that multiple activator and repressor pathways converge to regulate activation of the primordial follicle. First, primordial follicles spontaneously activate in vitro. Incubation with exogenous cytokines and growth factors increases the proportion of activated follicles and treatment with function blocking antibodies will suppress but not abolish primordial follicle activation suggesting other endogenous mechanisms (Kezele et al. 2002a, Hutt et al. $2006 a, b)$. This is corroborated by the inability of $\mathrm{AMH}$ and CXCL12 treatment to completely suppress follicle activation (Holt et al. 2006, Nilsson et al. 2007).

Secondly, studies of mice null for the ligands and their receptors implicated in follicle activation have indicated that their presence is not essential. Examples include the FGF2 knockout mouse, which is viable, fertile and has normal ovarian folliculogenesis (Dono etal. 1998). Similarly LIF knockout mouse females while infertile because of a defect in implantation, have normal folliculogenesis, ovarian morphology and oocytes that fertilize and implant in wild-type recipients (Stewart et al. 1992).

Thirdly, crosstalk between signalling pathways is crucial as knockout studies have also revealed that the neurotrophin, nerve growth factor (NGF) and its tyrosine receptor kinase $\mathrm{NTRK} 1$ are important in regulating follicular activation (Dissen et al. 2002, Romero et al. 2002). Two other neurotrophins (NTF5 and BDNF) and their receptor NTRK2 also appear to be highly influential in the survival of oocytes in neonatal mice with a role in primordial follicle maintenance (Romero et al. 2002, Paredes et al. 2004). Interestingly, treatment with FGF2 can overcome the effects of blocking NTRK2 signalling through rescuing oocytes from apoptosis, suggesting that at least two alternative coordinated pathways exist to ensure oocyte survival (Spears et al. 2003). Similarly, treatment of neonatal ovaries with the inhibitor $\mathrm{AMH}$ regulated the TGF $\beta$ signalling pathway, resulting in inhibition of primordial follicle development (Nilsson et al. 2007).

Fourthly, the identification of ligands with multiplicity of roles in folliculogenesis, such as the TGF $\beta$ ligands, GDF9 and BMP15, which are well recognized oocyte-derived regulatory proteins largely thought to have a role during pre-antral follicle development in addition to their facilitation of primordial follicle activation in some species. GDF9 ligand binds to the BMPRII and ALK type I receptor (Mazerbourg et al. 2004); however, the intracellular signalling cascades mediated by GDF9 are yet to be fully identified. The Gdf9 mRNA and protein have been located to the oocytes of primary follicles onwards in a number of species including the mouse (McGrath et al. 1995, Dong et al. 1996), rat (Hayashi et al. 1999, Jaatinen et al. 1999) and human (Aaltonen et al. 1999), whilst in the sheep and cow the primordial follicles also express GDF9 (Bodensteiner et al. 2000). The function of GDF9 in 
primordial follicle growth remains somewhat obscure. Treatment of immature rats with recombinant GDF9 in vivo leads to an increased rate of follicular activation (Vitt et al. 2000). Similarly, addition of recombinant rat GDF9 to human ovarian cortical slices in vitro increases the proportion of activated follicles as well as improving survival of follicles (Hreinsson et al. 2002). However, GDF9 null mice are infertile as ovarian follicles do not progress beyond the primary stage of folliculogenesis as granulosa cell proliferation is limited and the theca cell layer fails to develop (Dong et al. 1996). However, the oocyte growth is accelerated. This suggests that GDF9 may have a role in recruiting granulosa cells while limiting the growth of the oocyte. While BMP15 null mice are subfertile (Yan et al. 2001), sheep with BMP15 mutations have primary follicle stage arrest (McNatty et al. 2007). BMP15 has also been implicated in the regulation of KITL (Hutt \& Albertini 2007).

SMADS are downstream intracellular signalling molecules of the TGF $\beta$ ligands (BMP4 and BMP7) and several of the SMAD knockouts generated have been found embryonically lethal; however, the SMAD3 null mouse is viable. The SMAD3 null mouse has impaired folliculogenesis as the ovaries of young mice are normal while the adults have increased numbers of primordial follicles and decreased numbers of higher order follicles. SMAD3 deficiency slows follicle growth, causes atretic follicles, and lowers expression of the anti-apoptotic protein BCL2 (Kaivo-oja et al. 2006).

In light of the above, it is clear that these cytokine and growth factor-activated pathways interact to generate an intracellular balance of signals, ensuring maintenance of the quiescent primordial oocyte pool and controlled activation of primordial follicles from this finite population. However, the intracellular pathways by which these pleiotrophic cytokines influence follicle growth are only just being characterized.

\section{Intracellular signalling in oocytes and pregranulosa cells in primordial follicles}

Recently, one of the upstream transcription factors in the oocyte responsible for controlling expression of key genes in primordial to primary follicle transition was identified. Sohlh1 is a basic helix-loop-helix transcription factor, which is expressed in the germ cell clusters and in newly assembled primordial follicles. However, SOHLH1 protein expression disappears when the oocyte is activated to become a primordial follicle. The Sohlh1 null female mouse is infertile with the oocyte numbers decreasing from about normal at birth to none by 7 weeks of age. Further investigation revealed that there was an apparent defect at the primordial to primary follicle transition (Pangas et al. 2006).

As the time frame for oocyte loss is similar to that seen in Figla null mouse, and Sohlh1 null mice show a significant reduction in Figla transcripts and their targets (including the zona pellucida genes (Pangas et al. 2006), the authors speculated that SOHLH1 positively cooperates with this second transcription factor (FIGLA) in the transcriptional regulation of two of the zona pellucida genes (ZP1 and ZP3), hence the failure to transit into primary follicles (Pangas et al. 2006).

More recently the Sohlh2-deficient mouse has been described in which this germ cell-specific gene deletion also results in infertile adult mice in which the primordial follicles are abnormal. Again there is no differentiation of the surrounding pregranulosa cells into cuboidal and multilayered structures. Although there is limited growth, the primordial oocytes are abnormal in that several genes including Sohlh1, Nobox, Figla, Gdf9, Pou5f1, Zp1, Zp3, Kit, Oosp1, NIrp14, H1foo, and Stra8 are all misexpressed. The resultant phenotype is the rapid loss of oocytes in early post-natal life (Choi et al. 2008a).

In addition, there were several molecular similarities between the Sohlh1 and Sohlh2 null mice and the Nobox null mouse (newborn ovary homoeobox gene) (Rajkovic et al. 2004), in that the Gdf9, Pou5f1, Zar1, Moss and $H 1$ foo gene expression was down-regulated. Gene expression studies confirmed that the Sohlh1 and two null mice also had a significant reduction in the expression of the transcription factor gene, Nobox and that the Lhx8 (LIM homoeodomain protein) was also down-regulated; however, the function of $L h \times 8$ is unknown. Lhx8 knockouts have an identical ovarian phenotype to that of the Sohlh1 (Pangas et al. 2006). Chromatin immunoprecipitation assay (ChIP) analysis demonstrated that SOHLH1 bound directly to the promoters of $L h x 8, Z p 1$ and 3 but not to Nobox or $Z p 2$. It is likely that SOHLH1 binds directly to the Ebox found in the promoters of $L h \times 8, Z p 1$ and $Z p 3$ and regulates expression while it is unlikely that SOHLH1 directly controls the expression of Figla as this gene does not contain an Ebox in its promoter (Pangas et al. 2006). NOBOX binds to cis-acting NOBOX DNA-binding elements (NBEs) TAATTG, TAGTTG, TATTA and the promoters of Pou5f1 and Gdf9 both contain NBEs. This suggested that NOBOX regulates their transcription along with the finding that Nobox expression closely precedes expression of Pou5f1 and Gdf9 (Choi \& Rajkovic 2006b). Nobox null female mice are infertile with ovaries lacking oocytes by 6 weeks of age. However, the ovaries of Nobox null mice are normal before birth, in that ovarian development, germ cell proliferation and initial primordial follicle population was histomorphologically similar to the wild-type siblings. However, development of primary and secondary follicles did not occur in the null mice. Even though some of the oocytes were surrounded by cuboidal granulosa cells, the oocytes were very small and are continually lost from post-natal day 3 until only a few oocytes remained in the post-natal day 14 ovary.

Transcripts for Pou5f1, Gdf9 and Bmp 15 were downregulated in the null ovaries indicating that NOBOX may 
have a role in their regulation (Rajkovic et al. 2004). Recent analysis of the promoter activities of $\mathrm{H} 1 \mathrm{foO}, \mathrm{Npm} 2$ and Zar1 maternal genes in oocytes and pre-implantation embryos showed transcriptional activity in oocytes, but not in fertilized embryos. A putative Ebox region in the $\mathrm{H} 10 \mathrm{o}$ and the Npm2 promoters were required for basal transcriptional activity in oocytes and a putative NBE motif was shown to enhance basal transcriptional activity of the Npm2 promoter (Tsunemoto et al. 2008). In addition, a comparison of the expression level of genes regulated in LHX8 null and NOBOX null newborn ovaries indicated a common subset of genes was affected in both LHX8- and NOBOX-deficient mice (Choi et al. 2008b).

\section{Does a single pathway control primordial follicle activation?}

Of great current interest is the intracellular oocyte signalling pathway that controls FOXO3, a member of the forkhead transcription family, which has been implicated in a range of cellular functions including embryogenesis, tumorigenesis and maintenance of differentiated cell states through regulation of such cellular processes as metabolic cell cycle arrest, cellular stress response and apoptosis (Kaufmann \& Knochel 1996, Hosaka et al. 2004). Homozygous mutant mice display increased numbers of growing follicles, a lack of primordial follicles by 2 weeks of age and a subsequent increase in oocyte degeneration of newly growing follicles (Castrillon et al. 2003, Hosaka et al. 2004). Originally discovered to be expressed by the granulosa cells (Richards et al. 2002), the mechanisms by which FOXO3 mediated its suppressive effects on primordial follicle recruitment remained unclear. Brenkman and Burgering proposed a model whereby FOXO transcription factors arrest the cell cycle by increasing the expression of a cell cycle inhibitor, CDKN1B, whilst concurrently decreasing cyclin D1 and D2 expression (Brenkman \& Burgering 2003).

However, recent studies of a CDKN1B-deficient mouse model indicated that post-natal follicle assembly was accelerated, the initial population of primordial follicles was substantially increased and primordial follicle recruitment was prematurely activated (Rajareddy et al. 2007). This group determined that CDKN1B (or Cdkn1b) was also expressed in the oocyte and controlled oocyte development not by the usual control of the cell cycle progression but by suppressing the functions of Cdk2/CDC2A-cyclin A/E1 in diplotene-arrested oocytes (Rajareddy et al. 2007). Simultaneously, through activation of a caspase-mediated apoptotic cascade the authors propose that CDKN1B also induces follicle atresia (Rajareddy et al. 2007).

Upstream control of $\mathrm{FOXO} 3$ activation of protein kinase $B$ (Akt) via extracellular signalling pathways, such as that induced by insulin signalling, results in FOXO phosphorylation, and inactivation as a result of nuclear exclusion (Junger et al. 2003). The reported effect of insulin on follicle activation (Kezele et al. 2002b) may therefore involve FOXO3 inhibition and allow for the transcription of genes required for follicle activation. The presence of FOXO3 in follicles may also provide an explanation for how the quiescent primordial follicle is protected from oxidative stress as FOXO3 up-regulates expression of the superoxide-scavenger manganese superoxide dismutase (MnSOD) in mammalian cells (Kops et al. 2002).

\section{Signal transduction - the phosphatidylinositol 3-kinase (PI3K) pathway}

By contrast, studies of oocyte intracellular signalling pathways suggest that the $\mathrm{KL}$ produced by the granulosa cell binds to oocyte c-KIT receptor and the signal transduced through the PI3K pathway (Reddy et al. 2005) and this is important for the regulation of early follicular development (Liu et al. 2006). Components of the PI3K pathway, including Akt, FOXO3, GSK3A and GSK3B (Liu et al. 2007b), FOXO3 and CDKN1B have been shown to be present in growing mouse oocytes and the PIK3 pathway is stimulated in KL-treated in vitro cultured mouse and rat oocytes. These authors theorize that this signalling cascade, initiated by KL-activated oocyte surface C-KIT and followed by the subsequent activation of PI3K by c-KIT, may enhance oocyte growth and also the production of oocyte factors, which in turn stimulate the proliferation and differentiation of the surrounding granulosa cells. Simultaneously, KL-stimulated phosphorylation and functional suppression of FOXO3 may release the oocytes from their quiescent state allowing oocyte growth and development secretion (Liu et al. 2007a). This hypothesis was plausible given that $\mathrm{FOXO} 3$ has been shown to be capable of suppressing the production of BMP15, connexin 37 and connexin 43 in mouse oocytes, which are important for both oocyte granulosa and between granulosa cell communications, and to facilitate nuclear expression of p27 in the oocyte, which all lead to the arrest of oocyte growth and follicular development (Liu et al. 2006).

In 2008, an important piece of this signalling pathway was confirmed when Reddy, Liu, and colleagues published their findings on the ovary-specific conditional knockout of PTEN (phosphatase and tensin homolog deleted on chromosome 10) in oocytes, a major negative regulator of PI3K (Reddy et al. 2008). Like the FOXO3 null mouse, the entire primordial follicle pool becomes activated and all primordial follicles become depleted in early adulthood, causing POF. The authors concluded that this collective set of results suggested that mammalian oocyte is the initiator of follicle activation and that the oocyte PTEN-PI3K pathway governs follicle activation through control of initiation of oocyte growth (see Fig. 3).

Development of an oocyte-specific inducible conditional null (Vasa-Cre(ERT2) mouse has confirmed that 




Figure 3 The oocyte $\mathrm{KL}$ - PTEN-PI3K - FOXO3 pathway governs follicle activation through control of initiation of oocyte growth. Abbreviations: KL, KIT ligand; KIT, CD117 (c-KIT); PIP2, phosphatidyl inositol bisphosphatel; PI3K, phosphoinositide 3-kinase; PIP3, phosphatidylinositol $(3,4,5)$-trisphosphate; PDK1-3, phosphoinositidedependent protein kinase; Akt, protein kinase B; PTEN, phosphatase and tensin homolog; FOXO3, forkhead box O3A; GSK3, glycogen synthase kinase 3; CDKN1B, cyclin-dependent kinase inhibitor 1B (CDKN1); BMP15, bone morphogenic protein 15; Cx37, connexin 37; GDF9, growth differentiation factor 9 . the phosphoinositide 3-kinase (PI3K) signalling pathway does control primordial follicle activation (John et al. 2008), and that this is mediated through the forkhead transcription factor FOXO3. Evidence suggests that in oocytes during primordial follicle assembly the transcription factor FOXO3 is imported into the nucleus, and is re exported upon primordial follicle activation. Using oocyte-specific loss of PTEN to induce PI3K activation of Akt activation resulted in FOXO3 hyperphosphorylation, and $\mathrm{FOXO} 3$ nuclear export and this was concomitant with primordial follicle activation thus indicating that PI3K pathway and FOXO3 do in fact control primordial follicle activation (John et al. 2008).

\section{Conclusions}

Elegant work by Eppig and colleagues has demonstrated that once activated to grow, that oocytes orchestrate and coordinate the development of mammalian ovarian follicles and that the rate of follicle development is controlled by the oocyte (Eppig et al. 2002). However, primordial follicle activation appears to require close communication with somatic cells and therefore we conclude that since factors such as KL clearly demonstrate a role for granulosa cells in releasing oocytes into the growing pool, then if the trigger is oocyte generated, an early response must include suppression of FOXO3 activity. This further underscores the necessity of understanding not only the oocyte and granulosa pathways but also the signals between the cells. This has led to the speculation that a 'folliculogenesis clock' exists that is set by the oocyte (Matzuk et al. 2002). The discovery of more factors involved in the initiation of folliculogenesis will further aid in defining what triggers the mammalian follicle to leave the resting pool.

\section{Declaration of interest}

The authors declare that there is no conflict of interest that could be perceived as prejudicing the impartiality of the research reported. 


\section{Funding}

Funding was received from the Hunter Medical Research Institute Australia \& Permanent Charitable Foundation Grant No. HMRI 0634 and Australian Research Council.

\section{Acknowledgements}

The authors would like to acknowledge the contributions of Dr Janet Holt and Dr Daniel Blackmore for help with the illustrational and confocal images. The authors gratefully acknowledge the financial assistance to EAM by the Australian Research Council, Hunter Medical Research Institute and the Newcastle Permanent Building Society Charitable Trust.

\section{References}

Aaltonen J, Laitinen MP, Vuojolainen K, Jaatinen R, Horelli-Kuitunen N, Seppa L, Louhio H, Tuuri T, Sjoberg J, Butzow R et al. 1999 Human growth differentiation factor 9 (GDF-9) and its novel homolog GDF-9B are expressed in oocytes during early folliculogenesis. Journal of Clinical Endocrinology and Metabolism 84 2744-2750.

Allan CM, Wang Y, Jimenez M, Marshan B, Spaliviero J, Illingworth P \& Handelsman DJ 2006 Follicle-stimulating hormone increases primordial follicle reserve in mature female hypogonadal mice. Journal of Endocrinology 188 549-557.

Arraztoa JA, Zhou J, Marcu D, Cheng C, Bonner R, Chen M, Xiang C, Brownstein M, Maisey K, Imarai M et al. 2005 Identification of genes expressed in primate primordial oocytes. Human Reproduction 20 476-483.

Baird DT, Collins J, Egozcue J, Evers LH, Gianaroli L, Leridon H, Sunde A, Templeton A, Van Steirteghem A, Cohen J et al. 2005 Fertility and ageing. Human Reproduction Update 11 261-276.

Baker TG \& Franchi LL 1967 The fine structure of oogonia and oocytes in human ovaries. Journal of Cell Science 2 213-224.

Begum S, Papaioannou VE \& Gosden RG 2008 The oocyte population is not renewed in transplanted or irradiated adult ovaries. Human Reproduction 23 2326-2330.

Bodensteiner KJ, McNatty KP, Clay CM, Moeller CL \& Sawyer HR 2000 Expression of growth and differentiation factor-9 in the ovaries of fetal sheep homozygous or heterozygous for the inverdale prolificacy gene (FecX(I)). Biology of Reproduction 62 1479-1485.

Brenkman AB \& Burgering BM 2003 FoxO3a eggs on fertility and aging. Trends in Molecular Medicine 9 464-467.

Britt KL, Saunders PK, McPherson SJ, Misso ML, Simpson ER \& Findlay JK 2004 Estrogen actions on follicle formation and early follicle development. Biology of Reproduction 71 1712-1723.

Brook JD, Gosden RG \& Chandley AC 1984 Maternal ageing and aneuploid embryos - evidence from the mouse that biological and not chronological age is the important influence. Human Genetics 66 41-45.

Byskov AG, Faddy MJ, Lemmen JG \& Andersen CY 2005 Eggs forever? Differentiation 73 438-446.

Castrillon DH, Miao L, Kollipara R, Horner JW \& DePinho RA 2003 Suppression of ovarian follicle activation in mice by the transcription factor Foxo3a. Science 301 215-218.

Chen Y, Jefferson WN, Newbold RR, Padilla-Banks E \& Pepling ME 2007 Estradiol, progesterone, and genistein inhibit oocyte nest breakdown and primordial follicle assembly in the neonatal mouse ovary in vitro and in vivo. Endocrinology 148 3580-3590.

Choi Y \& Rajkovic A 2006 a Genetics of early mammalian folliculogenesis. Cellular and Molecular Life Sciences 63 579-590.

Choi Y \& Rajkovic A 2006b Characterization of NOBOX DNA binding specificity and its regulation of Gdf9 and Pou5f1 promoters. Journal of Biological Chemistry 281 35747-35756.

Choi Y, Yuan D \& Rajkovic A 2008a Germ cell-specific transcriptional regulator Soh/h2 is essential for early mouse folliculogenesis and oocyte-specific gene expression. Biology of Reproduction 79 1176-1172.
Choi Y, Ballow DJ, Xin Y \& Rajkovic A 2008b Lim homeobox gene, Ihx8, is essential for mouse oocyte differentiation and survival. Biology of Reproduction 79 442-449.

Craig J, Orisaka M, Wang H, Orisaka S, Thompson W, Zhu C, Kotsuji F \& Tsang BK 2007 Gonadotropin and intra-ovarian signals regulating follicle development and atresia: the delicate balance between life and death. Frontiers in Bioscience 12 3628-3639.

Demeestere I, Simon P, Emiliani S, Delbaere A \& Englert Y 2007 Fertility preservation: successful transplantation of cryopreserved ovarian tissue in a young patient previously treated for Hodgkin's disease. Oncologist 12 1437-1442.

Dissen GA, Romero C, Paredes A \& Ojeda SR 2002 Neurotrophic control of ovarian development. Microscopy Research and Technique 59 509-515.

Dole G, Nilsson E \& Skinner M 2008 Glial-derived neurotrophic factor promotes ovarian primordial follicle development and cell-cell interactions during folliculogenesis. Reproduction 135 671-682.

Dong J, Albertini DF, Nishimori K, Kumar TR, Lu N \& Matzuk MM 1996 Growth differentiation factor-9 is required during early ovarian folliculogenesis. Nature 383 531-535.

Dono R, Texido G, Dussel R, Ehmke H \& Zeller R 1998 Impaired cerebral cortex development and blood pressure regulation in FGF-2-deficient mice. EMBO Journal 17 4213-4225.

Durlinger AL, Gruijters MJ, Kramer P, Karels B, Ingraham HA, Nachtigal MW, Uilenbroek JT, Grootegoed JA \& Themmen AP 2002 Anti-Mullerian hormone inhibits initiation of primordial follicle growth in the mouse ovary. Endocrinology 143 1076-1084.

Edwards RG, Fowler RE, Gore-Langton RE, Gosden RG, Jones EC, Readhead C \& Steptoe PC 1977 Normal and abnormal follicular growth in mouse, rat and human ovaries. Journal of Reproduction and Fertility 51 237-263.

Eggan K, Jurga S, Gosden R, Min IM \& Wagers AJ 2006 Ovulated oocytes in adult mice derive from non-circulating germ cells. Nature 441 1109-1114.

Eppig JJ 2001 Oocyte control of ovarian follicular development and function in mammals. Reproduction 122 829-938.

Eppig JJ \& O'Brien MJ 1996 Development in vitro of mouse oocytes from primordial follicles. Biology of Reproduction 54 197-207.

Eppig JJ, Wigglesworth K \& Pendola FL 2002 The mammalian oocyte orchestrates the rate of ovarian follicular development. PNAS99 2890-2894.

Faddy MJ 2000 Follicle dynamics during ovarian ageing. Molecular and Cellular Endocrinology 163 43-48.

Faddy MJ \& Gosden RG 1996 A model conforming the decline in follicle numbers to the age of menopause in women. Human Reproduction 11 1484-1486.

Gondos B 1987a Comparative studies of normal and neoplastic ovarian germ cells: 1. Ultrastructure of oogonia and intercellular bridges in the fetal ovary. International Journal of Gynecological Pathology 6 114-123.

Gondos B 1987b Comparative studies of normal and neoplastic ovarian germ cells: 2. Ultrastructure and pathogenesis of dysgerminoma. International Journal of Gynecological Pathology 6 124-131.

Gougeon A \& Chainy GB 1987 Morphometric studies of small follicles in ovaries of women at different ages. Journal of Reproduction and Fertility 81 433-442.

Gougeon A, Ecochard R \& Thalabard JC 1994 Age-related changes of the population of human ovarian follicles: increase in the disappearance rate of non-growing and early-growing follicles in aging women. Biology of Reproduction $\mathbf{5 0}$ 653-663.

Hage AJ, Groen-Klevant AC \& Welschen R 1978 Follicle growth in the immature rat ovary. Acta Endocrinologica 88 375-382.

Hansen KR, Knowlton NS, Thyer AC, Charleston JS, Soules MR \& Klein NA 2008 A new model of reproductive aging: the decline in ovarian non-growing follicle number from birth to menopause. Human Reproduction 23 699-708.

Hayashi M, McGee EA, Min G, Klein C, Rose UM, van Duin M \& Hsueh AJ 1999 Recombinant growth differentiation factor-9 (GDF-9) enhances growth and differentiation of cultured early ovarian follicles. Endocrinology 140 1236-1244.

Henderson SA \& Edwards RG 1968 Chiasma frequency and maternal age in mammals. Nature 218 22-28.

Hirshfield AN 1991 Development of follicles in the mammalian ovary. International Reviews of Cytology 124 43-101.

Hirshfield AN 1992 Heterogeneity of cell populations that contribute to the formation of primordial follicles in rats. Biology of Reproduction 47 466-472.

Holt JE, Jackson A, Roman SD, Aitken RJ, Koopman P \& McLaughlin EA 2006 CXCR4/SDF1 interaction inhibits the primordial to primary follicle transition in the neonatal mouse ovary. Developmental Biology 293 449-460. 
Hosaka T, Biggs WH III, Tieu D, Boyer AD, Varki NM, Cavenee WK \& Arden KC 2004 Disruption of forkhead transcription factor (FOXO) family members in mice reveals their functional diversification. PNAS 101 2975-2980.

Hreinsson JG, Scott JE, Rasmussen C, Swahn ML, Hsueh AJ \& Hovatta O 2002 Growth differentiation factor-9 promotes the growth, development, and survival of human ovarian follicles in organ culture. Journal of Clinical Endocrinology and Metabolism 87 316-321.

Hunter MG, Robinson RS, Mann GE \& Webb R 2004 Endocrine and paracrine control of follicular development and ovulation rate in farm species. Animal Reproduction Science 82-83 461-477.

Hutt KJ \& Albertini DF 2007 An oocentric view of folliculogenesis and embryogenesis. Reproductive Biomedicine Online 14 758-764.

Hutt KJ, McLaughlin EA \& Holland MK 2006a Kit Ligand and c-Kit have diverse roles during mammalian oogenesis and folliculogenesis. Molecular Human Reproduction 12 61-69.

Hutt KJ, McLaughlin EA \& Holland MK 2006 $b$ KIT/KIT ligand in mammalian oogenesis and folliculogenesis: roles in rabbit and murine ovarian follicle activation and oocyte growth. Biology of Reproduction 75 421-433.

Jaatinen $\mathbf{R}$, Laitinen MP, Vuojolainen $\mathrm{K}$, Aaltonen J, Louhio $\mathbf{H}$, Heikinheimo K, Lehtonen E \& Ritvos O 1999 Localization of growth differentiation factor-9 (GDF-9) mRNA and protein in rat ovaries and cDNA cloning of rat GDF-9 and its novel homolog GDF-9B. Molecular and Cellular Endocrinology 156 189-193.

John GB, Gallardo TD, Shirley LJ \& Castrillon DH 2008 Foxo3 is a PI3Kdependent molecular switch controlling the initiation of oocyte growth. Developmental Biology 321 197-204.

Johnson J, Canning K, Kaneko T, Pru JK \& Tilly JL 2004 Germline stem cells and follicular renewal in the postnatal mammalian ovary. Nature 428 145-150.

Johnson J, Bagley J, Skaznik-Wikiel M, Lee HJ, Adams GB, Niikura Y, Tschudy KS, Tilly JC, Cortes ML, Forkert R et al. 2005 Oocyte generation in adult mammalian ovaries by putative germ cells in bone marrow and peripheral blood. Cell 122 303-315.

Joshi S, Davies H, Sims LP, Levy SE \& Dean J 2007 Ovarian gene expression in the absence of FIGLA, an oocyte-specific transcription factor. BMC Developmental Biology 767.

Junger MA, Rintelen F, Stocker H, Wasserman JD, Vegh M, Radimerski T, Greenberg ME \& Hafen E 2003 The Drosophila forkhead transcription factor FOXO mediates the reduction in cell number associated with reduced insulin signaling. Journal of Biology 22.

Kaivo-oja N, Jeffery LA, Ritvos O \& Mottershead DG 2006 Smad signalling in the ovary. Reproductive Biology and Endocrinology 421.

Kaufmann E \& Knochel W 1996 Five years on the wings of fork head. Mechanisms of Development 57 3-20.

Kehler J, Tolkunova E, Koschorz B, Pesce M, Gentile L, Boiani M, Lomeli H, Nagy A, McLaughlin KJ, Scholer HR et al. 2004 Oct4 is required for primordial germ cell survival. EMBO Reports 5 1078-1083.

Kerr JB, Duckett R, Myers M, Britt KL, Mladenovska T \& Findlay JK 2006 Quantification of healthy follicles in the neonatal and adult mouse ovary: evidence for maintenance of primordial follicle supply. Reproduction 132 95-109.

Kezele P \& Skinner MK 2003 Regulation of ovarian primordial follicle assembly and development by estrogen and progesterone: endocrine model of follicle assembly. Endocrinology 144 3329-3337.

Kezele P, Nilsson E \& Skinner MK 2002a Cell-cell interactions in primordial follicle assembly and development. Frontiers in Bioscience 7 d1990-d1996.

Kezele PR, Nilsson EE \& Skinner MK 2002b Insulin but not insulin-like growth factor-1 promotes the primordial to primary follicle transition. Molecular and Cellular Endocrinology 192 37-43.

Kezele P, Nilsson EE \& Skinner MK 2005a Keratinocyte growth factor acts as a mesenchymal factor that promotes ovarian primordial to primary follicle transition. Biology of Reproduction 73 967-973.

Kezele PR, Ague JM, Nilsson E \& Skinner MK 2005b Alterations in the ovarian transcriptome during primordial follicle assembly and development. Biology of Reproduction 72 241-255.

Kim MR \& Tilly JL 2004 Current concepts in Bcl-2 family member regulation of female germ cell development and survival. Biochimica et Biophysica Acta 1644 205-210.

Kops GJ, Dansen TB, Polderman PE, Saarloos I, Wirtz KW, Coffer PJ, Huang TT, Bos JL, Medema RH \& Burgering BM 2002 Forkhead transcription factor FOXO3a protects quiescent cells from oxidative stress. Nature 419 316-321.
Kunwar PS, Siekhaus DE \& Lehmann R 2006 In vivo migration: a germ cell perspective. Annual Review of Cell and Developmental Biology 22 237-265.

Lee WS, Otsuka F, Moore RK \& Shimasaki S 2001 Effect of bone morphogenetic protein-7 on folliculogenesis and ovulation in the rat. Biology of Reproduction 65 994-999.

Lee HJ, Selesniemi K, Niikura Y, Niikura T, Klein R, Dombkowski DM \& Tilly JL 2007a Bone marrow transplantation generates immature oocytes and rescues long-term fertility in a preclinical mouse model of chemotherapy-induced premature ovarian failure. Journal of Clinical Oncology 25 3198-3204.

Lee HJ, Sakamoto $H$, Luo $H$, Skaznik-Wikiel ME, Friel AM, Niikura T, Tilly JC, Niikura Y, Klein R, Styer AK et al. 2007b Loss of CABLES1, a cyclin-dependent kinase-interacting protein that inhibits cell cycle progression, results in germline expansion at the expense of oocyte quality in adult female mice. Cell Cycle 6 2678-2684.

Liang L, Soyal SM \& Dean J 1997 FIGalpha, a germ cell specific transcription factor involved in the coordinate expression of the zona pellucida genes. Development 124 4939-4947.

Liu K, Rajareddy S, Liu L, Jagarlamudi K, Boman K, Selstam G \& Reddy P 2006 Control of mammalian oocyte growth and early follicular development by the oocyte PI3 kinase pathway: new roles for an old timer. Developmental Biology 299 1-11.

Liu L, Rajareddy S, Reddy P, Du C, Jagarlamudi K, Shen Y, Gunnarsson D, Selstam G, Boman K \& Liu K 2007 a Infertility caused by retardation of follicular development in mice with oocyte-specific expression of Foxo3a. Development 134 199-209.

Liu L, Rajareddy S, Reddy P, Jagarlamudi K, Du C, Shen Y, Guo Y, Boman K, Lundin E, Ottander U et al. 2007b Phosphorylation and inactivation of glycogen synthase kinase-3 by soluble kit ligand in mouse oocytes during early follicular development. Journal of Molecular Endocrinology 38 137-146.

Liu Y, Wu C, Lyu Q, Yang D, Albertini DF, Keefe DL \& Liu L 2007 c Germline stem cells and neo-oogenesis in the adult human ovary. Developmental Biology 306 112-120.

Maheshwari A \& Fowler PA 2008 Primordial follicular assembly in humans - revisited. Zygote 16 285-296.

Mahmoud MS, Merhi ZO \& Yelian FD 2007 Mechanisms of premature ovarian failure: reappraisal and overview. Journal of Reproductive Medicine 52 623-629.

Mandl AM \& Zuckerman S 1951 The relation of age to numbers of oocytes. Journal of Endocrinology 7 190-193.

Mattiske D, Kume T \& Hogan BL 2006 The mouse forkhead gene Foxc1 is required for primordial germ cell migration and antral follicle development. Developmental Biology 290 447-458.

Matzuk MM, Burns KH, Viveiros MM \& Eppig JJ 2002 Intercellular communication in the mammalian ovary: oocytes carry the conversation. Science 296 2178-2180.

Mazerbourg S, Klein C, Roh J, Kaivo-Oja N, Mottershead DG, Korchynskyi O, Ritvos O \& Hsueh AJ 2004 Growth differentiation factor-9 signaling is mediated by the type I receptor, activin receptor-like kinase 5. Molecular Endocrinology 18 653-665.

McGee EA \& Hsueh AJ 2000 Initial and cyclic recruitment of ovarian follicles. Endocrine Reviews 21 200-214.

McGrath SA, Esquela AF \& Lee SJ 1995 Oocyte-specific expression of growth/differentiation factor-9. Molecular Endocrinology 9 131-136.

McLaughlin EA, Holland MK \& Aitken RJ 2003 Contraceptive vaccines. Expert Opinion on Biological Therapy 3 829-841.

McNatty KP, Fidler AE, Juengel JL, Quirke LD, Smith PR, Heath DA, Lundy T, O'Connell A \& Tisdall DJ 2000 Growth and paracrine factors regulating follicular formation and cellular function. Molecular and Cellular Endocrinology 163 11-20.

McNatty KP, Reader K, Smith P, Heath DA \& Juengel JL 2007 Control of ovarian follicular development to the gonadotrophin-dependent phase: a 2006 perspective. Society of Reproduction and Fertility 64 55-68.

Meredith S \& Doolin D 1997 Timing of activation of primordial follicles in mature rats is only slightly affected by fetal stage at meiotic arrest. Biology of Reproduction 57 63-67.

Molyneaux K \& Wylie C 2004 Primordial germ cell migration. International Journal of Developmental Biology 48 537-544.

Nilsson EE \& Skinner MK 2003 Bone morphogenetic protein-4 acts as an ovarian follicle survival factor and promotes primordial follicle development. Biology of Reproduction 69 1265-1272. 
Nilsson E, Parrott JA \& Skinner MK 2001 Basic fibroblast growth factor induces primordial follicle development and initiates folliculogenesis. Molecular and Cellular Endocrinology 175 123-130.

Nilsson EE, Kezele P \& Skinner MK 2002 Leukemia inhibitory factor (LIF) promotes the primordial to primary follicle transition in rat ovaries. Molecular and Cellular Endocrinology 188 65-73.

Nilsson EE, Detzel C \& Skinner MK 2006a Platelet-derived growth factor modulates the primordial to primary follicle transition. Reproduction $\mathbf{1 3 1}$ 1007-1015.

Nilsson EE, Stanfield J \& Skinner MK 2006b Interactions between progesterone and tumor necrosis factor-alpha in the regulation of primordial follicle assembly. Reproduction 132 877-886.

Nilsson E, Rogers N \& Skinner MK 2007 Actions of anti-Mullerian hormone on the ovarian transcriptome to inhibit primordial to primary follicle transition. Reproduction 134 209-221.

Pangas SA \& Rajkovic A 2006 Transcriptional regulation of early oogenesis: in search of masters. Human Reproduction Update 12 65-76.

Pangas SA, Choi Y, Ballow DJ, Zhao Y, Westphal H, Matzuk MM \& Rajkovic A 2006 Oogenesis requires germ cell-specific transcriptional regulators Sohlh1 and Lhx8. PNAS 103 8090-8095.

Paredes A, Romero C, Dissen GA, DeChiara TM, Reichardt L, Cornea A, Ojeda SR \& Xu B 2004 TrkB receptors are required for follicular growth and oocyte survival in the mammalian ovary. Developmental Biology 267 430-449.

Parfenov VN, Pochukalina GN, Davis DS, Reinbold R, Scholer HR \& Murti KG 2003 Nuclear distribution of Oct-4 transcription factor in transcriptionally active and inactive mouse oocytes and its relation to RNA polymerase II and splicing factors. Journal of Cellular Biochemistry 89 720-732.

Pedersen T 1969 Follicle growth in the immature mouse ovary. Acta Endocrinologica 62 117-132.

Pepling ME 2006 From primordial germ cell to primordial follicle: mammalian female germ cell development. Genesis 44 622-632.

Pepling ME \& Spradling AC 1998 Female mouse germ cells form synchronously dividing cysts. Development 125 3323-3328.

Pepling ME \& Spradling AC 2001 Mouse ovarian germ cell cysts undergo programmed breakdown to form primordial follicles. Developmental Biology 234 339-351.

Picton H, Briggs D \& Gosden R 1998 The molecular basis of oocyte growth and development. Molecular and Cellular Endocrinology 145 27-37.

Polani PE \& Crolla JA 1991 A test of the production line hypothesis of mammalian oogenesis. Human Genetics 88 64-70.

Pukazhenthi B, Comizzoli P, Travis AJ \& Wildt DE 2006 Applications of emerging technologies to the study and conservation of threatened and endangered species. Reproduction, Fertility, and Development 18 77-90.

Rajareddy S, Reddy P, Du C, Liu L, Jagarlamudi K, Tang W, Shen Y, Berthet C, Peng SL, Kaldis P et al. 2007 p27kip1 (cyclin-dependent kinase inhibitor $1 \mathrm{~B}$ ) controls ovarian development by suppressing follicle endowment and activation and promoting follicle atresia in mice. Molecular Endocrinology 21 2189-2202.

Rajkovic A, Pangas SA, Ballow D, Suzumori N \& Matzuk MM 2004 NOBOX deficiency disrupts early folliculogenesis and oocyte-specific gene expression. Science 305 1157-1159.

Reddy P, Shen L, Ren C, Boman K, Lundin E, Ottander U, Lindgren P, Liu YX, Sun QY \& Liu K 2005 Activation of Akt (PKB) and suppression of FKHRL1 in mouse and rat oocytes by stem cell factor during follicular activation and development. Developmental Biology 281 160-170.

Reddy P, Liu L, Adhikari D, Jagarlamudi K, Rajareddy S, Shen Y, Du C, Tang W, Hamalainen T, Peng SL et al. 2008 Oocyte-specific deletion of Pten causes premature activation of the primordial follicle pool. Science $319611-613$.

Reynaud K \& Driancourt MA 2000 Oocyte attrition. Molecular and Cellular Endocrinology 163 101-108.

Richards JS, Russell DL, Ochsner S, Hsieh M, Doyle KH, Falender AE, Lo YK \& Sharma SC 2002 Novel signaling pathways that control ovarian follicular development, ovulation, and luteinization. Recent Progress in Hormone Research 57 195-220.

Romero C, Paredes A, Dissen GA \& Ojeda SR 2002 Nerve growth factor induces the expression of functional FSH receptors in newly formed follicles of the rat ovary. Endocrinology 143 1485-1494.
Roy SK \& Albee L 2000 Requirement for follicle-stimulating hormone action in the formation of primordial follicles during perinatal ovarian development in the hamster. Endocrinology 141 4449-4456.

Sathananthan AH, Selvaraj K \& Trounson A 2000 Fine structure of human oogonia in the foetal ovary. Molecular and Cellular Endocrinology 161 3-8.

Schmidt KL, Kryger-Baggesen N, Byskov AG \& Andersen CY 2005 AntiMullerian hormone initiates growth of human primordial follicles in vitro. Molecular and Cellular Endocrinology 234 87-93.

Serafica MD, Goto T \& Trounson AO 2005 Transcripts from a human primordial follicle cDNA library. Human Reproduction 20 2074-2091.

Sforza C \& Forabosco A 1998 A morphometric approach to the study of human ovarian organogenesis. Italian Journal of Anatomy and Embryology 103 51-62.

Skaznik-Wikiel M, Tilly JC, Lee HJ, Niikura Y, Kaneko-Tarui T, Johnson J \& Tilly JL 2007 Serious doubts over 'Eggs forever?' Differentiation 75 93-99.

Skinner MK 2005 Regulation of primordial follicle assembly and development. Human Reproduction Update 11 461-471.

Soyal SM, Amleh A \& Dean J 2000 FIGalpha, a germ cell-specific transcription factor required for ovarian follicle formation. Development 127 4645-4654.

Spears N, Molinek MD, Robinson LL, Fulton N, Cameron H, Shimoda K, Telfer EE, Anderson RA \& Price DJ 2003 The role of neurotrophin receptors in female germ-cell survival in mouse and human. Development 130 5481-5491.

Stewart CL, Kaspar P, Brunet LJ, Bhatt H, Gadi I, Kontgen F \& Abbondanzo SJ 1992 Blastocyst implantation depends on maternal expression of leukaemia inhibitory factor. Nature 359 76-79.

Suzumori N, Pangas SA \& Rajkovic A 2007 Candidate genes for premature ovarian failure. Current Medicinal Chemistry 14 353-357.

Telfer EE, Gosden RG, Byskov AG, Spears N, Albertini D, Anderson CY, Anderson R, Braw-Tal R, Clarke H \& McLoughlin E 2005 On regenerating the ovary and generating controversy. Cell 122 821-822.

Tilly JL \& Johnson J 2007 Recent arguments against germ cell renewal in the adult human ovary: is an absence of marker gene expression really acceptable evidence of an absence of oogenesis? Cell Cycle 6 879-883.

Tilly JL \& Rueda BR 2008 Minireview: stem cell contribution to ovarian development, function, and disease. Endocrinology 149 4307-4311.

Tilly JL, Niikura Y \& Rueda BR 2008 The current status of evidence for and against postnatal oogenesis in mammals: a case of ovarian optimism versus pessimism? Biology of Reproduction [in press] DOI: 10.1095/biolreprod.108.069088.

Tsunemoto K, Anzai M, Matsuoka T, Tokoro M, Shin SW, Amano T, Mitani T, Kato H, Hosoi Y, Saeki K et al. 2008 Cis-acting elements (E-box and NBE) in the promoter region of three maternal genes (Histone H1oo, Nucleoplasmin 2, and Zygote Arrest 1) are required for oocyte-specific gene expression in the mouse. Molecular Reproduction and Development 75 1104-1108.

Vitt UA, McGee EA, Hayashi M \& Hsueh AJ 2000 In vivo treatment with GDF9 stimulates primordial and primary follicle progression and theca cell marker CYP17 in ovaries of immature rats. Endocrinology 141 3814-3820.

Wandji SA, Srsen V, Voss AK, Eppig JJ \& Fortune JE 1996 Initiation in vitro of growth of bovine primordial follicles. Biology of Reproduction 55 942-948.

van Wezel IL \& Rodgers RJ 1996 Morphological characterization of bovine primordial follicles and their environment in vivo. Biology of Reproduction 55 1003-1011.

Yan C, Wang P, DeMayo J, DeMayo FJ, Elvin JA, Carino C, Prasad SV, Skinner SS, Dunbar BS, Dube JL et al. 2001 Synergistic roles of bone morphogenetic protein 15 and growth differentiation factor 9 in ovarian function. Molecular Endocrinology 15 854-866.

Zheng P \& Dean J 2007 Oocyte-specific genes affect folliculogenesis, fertilization, and early development. Seminars in Reproductive Medicine 25 243-251.

Zuckerman S 1951 The number of oocytes in the mature ovary. Recent Progress in Hormone Research 6 63-108.

Received 16 March 2008

First decision 23 April 2008

Revised manuscript received 6 September 2008

Accepted 30 September 2008 